\title{
Evolución y desarrollo del eslogan publicitario: tercer análisis
}

\author{
Manuel GARRIDO LORA, Juan REY, Marina RAMOS SERRANO ${ }^{1}$ \\ Universidad de Sevilla
}

\begin{abstract}
RESUMEN:
El objeto de este trabajo viene determinado por la tradicional atención que suscitan los eslóganes en el ámbito académico y la necesidad de estudiar su evolución y desarrollo en el contexto actual de la comunicación publicitaria española. Su finalidad es retratar la situación del eslogan en la publicidad gráfica española y, al mismo tiempo, cotejar los resultados con los estudios anteriores a fin de observar la evolución del mismo en aspectos como la economía expresiva, la densidad semántica, el uso de recursos retóricos, la perdurabilidad, la exclusividad o la eficiencia comunicativa. Esta investigación se inserta, pues, en el campo de los estudios sobre los contenidos de los medios de comunicación (mass communication research), en los que la técnica del análisis de contenido (content analysis) ha dado resultados satisfactorios. Para ello, se ha analizado un extenso corpus de eslóganes aparecidos en la prensa española durante 2011. Resumidamente, puede afirmarse que se estabilizan las tendencias ya anotadas en estudios precedentes: menos uso del eslogan, mayor brevedad y concentración expresiva, más recursos retóricos, más protagonismo del consumidor en su concepto, más eslóganes en lenguas distintas al castellano, etc.
\end{abstract}

PALABRAS CLAVE: Eslogan; redacción publicitaria; publicidad gráfica; retórica; crisis económica.

TITLE: Evolution and development of the advertising slogan: further analysis.

\begin{abstract}
:
The purpose of this work is determined by the typical interest aroused in academia by slogans and the need to study their evolution and development in the current context of Spanish advertising communication. Its aim is to portray the state of slogans in Spanish print advertising, and at the same time, to compare the results to those of previous studies in order to observe its evolution in certain areas, such as the economy of expression, the semantic density, the use of rhetorical tropes, perdurability, exclusivity, and communication efficiency. The present research is therefore in line with mass communication research, within which the technique of content analysis has proved itself to be an effective tool. To this end, an extensive corpus of advertising slogans appearing in newspapers during 2011 was analyzed. In short, it can be stated that trends noted in previous studies are reinforced: a decrease in the use of slogans, more brevity and expressive condensation, more rhetorical tropes, a more active role of the consumer in creative concepts, and an increase in the number of advertising slogans in languages other than Spanish.
\end{abstract}

KEY WORDS: Slogan; advertising copywriting; print advertising; rhetoric; economic crisis.

1 Los tres autores son doctores en Comunicación (sección Publicidad); Profesores Titulares de Universidad adscritos al departamento de Comunicación Audiovisual y Publicidad de la Facultad de Comunicación de la Universidad de Sevilla; e integrantes del grupo de investigación en Métodos, Análisis y Estrategias de la Comunicación Empresarial e Institucional (MAECEI). Sus correos electrónicos son respectivamente: mgarri@us.es, juanrey@us.es y mramos@us.es 


\section{Antecedentes, justificación y definición de objetivos}

El equipo de investigación en Métodos, Análisis y Estrategias de la Comunicación Empresarial e Institucional (MAECEI) de la Universidad de Sevilla ha mostrado desde sus inicios (1995) una especial sensibilidad con el estudio de la creatividad publicitaria y, especialmente, con la redacción publicitaria. Hace una década, uno de sus integrantes (Garrido, 2000) publicó en Questiones Publicitarias un análisis del contenido de los eslóganes aparecidos en la publicidad gráfica española en el medio prensa (prensa diaria, suplementos y revistas) con el objetivo de observar su evolución con respecto a los estudios teóricos y cuantitativos precedentes (Haas, 1966; Reboul, 1978; Díez de Castro y Galán, 1988; Spang, 1991; Ortega, 1992; Bassat, 1994; y Rey, 1996). Dicho estudio concluía con un compromiso de reedición cada lustro, con el objetivo de radiografiar periódicamente la evolución formal y conceptual de esta importante unidad redaccional. Posteriormente, dos investigadores del equipo (Garrido y Ramos, 2006), presentaron, en el Congreso Internacional Comunicación y Realidad (Universitat Ramon Llull, Barcelona), la primera reedición del estudio, en el que se analizó la publicidad emitida en 2005. El presente trabajo es, pues, la tercera edición de este estudio, y en él, además de la observación del progreso y evolución de los aspectos formales y cualitativos del eslogan (objetivo principal), interesa saber asimismo en qué medida el contexto actual de crisis ha podido influir en aspectos como la economía expresiva, la densidad semántica, la brillantez y uso de recursos retóricos, la perdurabilidad, la exclusividad o la eficacia comunicativa de los eslóganes (objetivo secundario).

\section{Conceptualización y evolución histórica del eslogan}

El eslogan publicitario hunde sus raíces en la retórica clásica, que aboga por la conclusión del discurso con una frase o expresión breve que condense de manera brillante y perdurable lo expuesto con anterioridad. El discurso publicitario ha heredado este y otros muchos principios de la retórica clásica, y el eslogan es consecuencia de ello. Aunque en el ámbito profesional, tan dado a los anglicismos, se sigue empleando el término slogan, en el ámbito académico se ha consolidado la castellanización de la misma mediante la preferencia de la palabra 'eslogan', que la Real Academia Española define como una «fórmula breve y original, utilizada para publicidad, propaganda política, etc.» (2001). En todo caso, ambos términos derivan de la expresión gaélica sluagh-gairm, que

era el grito de guerra con el que se daban ánimos los guerreros, aquel grito que les impulsaba a la batalla en la que probablemente perdiesen la vida. Si una frase podía hacer aquello, podía cegar a un hombre hasta estar dispuesto a una acción que implicaba riesgo vital, ¿qué no podría hacer por un jabón, un chocolate o una marca de conservas? (Eguizábal, 2007: 23). 
Con el paso del tiempo, el sistema parlamentario británico adoptó el vocablo en su aplicación a los procesos electorales. En el siglo XIX, la manifiesta influencia anglosajona sobre la cultura norteamericana y la pujanza mercantilista estadounidense hicieron el resto para que el eslogan se convirtiera en un pieza clave de la comunicación comercial, si bien es cierto que en Estados Unidos se ha empleado en ocasiones para designar indistintamente tanto a headlines, o titulares, como a baselines, o eslóganes en sentido estricto (Burton, 1990: 54). El desarrollo de la prensa de gran tirada propiciará, sobre todo en la segunda mitad del siglo XIX, una publicidad en prensa más elaborada cuyos textos anticipan lo que será la redacción publicitaria del siguiente siglo. En estos anuncios, el eslogan comienza a ser un recurso habitual con el que los anunciantes persiguen la memorabilidad de sus mensajes y la persuasión de los lectores. Evidentemente, en esta época y debido a la escasa calidad de la mayoría de sistemas de impresión, toda la fuerza del eslogan va a radicar en sus aspectos semánticos, que décadas después -en pleno siglo XXse verán apoyados en un serio trabajo tipográfico una vez mejorada la calidad de impresión. Desde finales del siglo XIX, y en paralelo a su uso comercial, el eslogan resurge como instrumento destacado de la comunicación política, tanto en el ámbito democrático como en los frecuentes totalitarismos que conoce la primera mitad del siglo XX. De este modo,

puede decirse que la trayectoria del eslogan es la historia de un vaivén entre dos polos. Pasa, primero, de la política a la publicidad: de consigna electoral inglesa a frase publicitaria norteamericana. Luego, regresa de la publicidad a la política: de frase comercial estadounidense a consigna totalitaria. Después, va nuevamente de la política a la publicidad: de consigna nazi a frase publicitaria. Y, por último, se usa tanto en la comunicación empresarial como en la institucional (Rey, 1996: 112).

Como se ha comentado anteriormente, muchos autores se han aproximado al estudio del eslogan, la mayoría en su vertiente comercial, pero también otros desde la perspectiva de la comunicación política o propagandística: Haas (1966), Reboul (1978), Díez de Castro y Galán (1988), Spang (1991), Ortega (1992), Bassat (1994), Rey (1996), Adam y Bonhomme (2000), Garrido (2000), Peña (2001), Fernández Gómez (2005), Muñiz (2005), Ortega et al. (2006); Garrido y Ramos (2006), Hernández (2007), etc. También son numerosos los estudios sobre el eslogan en el ámbito anglosajón, principalmente aquellos centrados en su eficacia y en sectores especializados: Kemp et al. (2012), Samuelsen \& Olsen (2010), Fay (1999), Chan (2000).Y el mismo Prat Gaballí (1998), hoy reconocido como uno de los primeros teóricos de la publicidad en todo el mundo, ya mostró interés por los eslóganes a principios del siglo XX. Todos ellos han contribuido a la configuración teórica del eslogan y han aportado en muchos casos definiciones del mismo (Garrido, 2000, pp. 69-70). En todo caso, se echan en falta en España estudios que aborden la eficacia comunicativa del eslogan, más allá de los lugares comunes en los que se reincide: 
La investigación sobre el funcionamiento del eslogan, y también del mensaje publicitario en general, está demandando mayor número de estudios empíricos, sobre todo en nuestro país, que hagan viable fundamentar lo más científicamente posible el conjunto de afirmaciones y pautas que sobre el eslogan se dicen y escriben (Muñiz, 2005: 119).

En el presente estudio se define el eslogan como "la expresión lingüística económica, significativa, brillante, perdurable, exclusiva y eficiente de una estrategia de comunicación empresarial, política o institucional" (Garrido, 2000: 70). Aunque el enfoque de la investigación es académico, debe saberse también que la profesión publicitaria emplea hoy otros muchos términos - claim, sobre todo- para referirse al eslogan. El director creativo Hollander lo ha expresado claramente: "Al principio fue el eslogan, una palabra que era la esencia de la publicidad y que nadie utilizaría hoy [...]. Claim, eslogan, tag line, base line, cierre, end line [...], todo para decir lo mismo" (2007: 19).

\section{Cuestiones metodológicas}

Una vez presentado muy brevemente el marco teórico, los antecedentes y la definición conceptual del objeto de estudio, se procede a reseñar la metodología aplicada. Esta investigación, que entiende el eslogan como unidad comunicativa y redaccional, se sitúa en el campo de los estudios sobre el discurso y los contenidos de los medios de comunicación (mass communication research), donde la técnica del análisis de contenido (content analysis) ha generado resultados muy satisfactorios, convirtiéndose en uno de los procedimientos más populares para «formular, a partir de ciertos datos, inferencias reproducibles y válidas que puedan aplicarse a su contexto» (Krippendorff, 1990: 28). Además, se trata de una técnica no intromisiva, útil para aquellos casos -como el presente- en los que se emplean códigos de interpretación no unívoca, sensible al contexto de emisión, y entiende los datos como fenómenos simbólicos, lo que le aproxima a la retórica propia de la comunicación publicitaria.

Con este método, se ha seleccionado un corpus de 400 anuncios distintos aparecidos en la publicidad gráfica española en la prensa diaria, las revistas y los suplementos dominicales durante 2011. Los soportes se han seleccionado por su elevado nivel de audiencia y por su capacidad para representar a diversos tipos de anunciantes. Son los siguientes: El País, As, Magazine de El Mundo, Magazine, El País Semanal, XL Semanal, Diez Minutos, Semana, Pronto, QMD, AR, ELLE, Telva, El Mueble, QUO, Muy Interesante, Autopista, Car\&Driver y Paisajes desde el tren. De cada uno de estos soportes, se han tomado varios números (76 en total); y de estos se han seleccionado todos los anuncios de gran formato. La mayoría son anuncios de página completa, pero también se han seleccionado los de doble página, los robapáginas y algunas dobles columnas y faldones con capacidad expresiva 
razonable. Se han desechado, en primer lugar, las repeticiones, y, en segundo lugar, aquellos anuncios cuya estructura modular reducida imposibilitara un trabajo completo de copy en el mismo y, en consecuencia, un análisis comparativamente homogéneo entre todas las unidades de análisis. Cada anuncio ha sido sometido una ficha de análisis que incluye las siguientes variables: la presencia o ausencia de eslogan, el tipo de anunciante, el producto o servicio anunciado, la localización del mismo, el texto completo del eslogan, la presencia de doble eslogan, el idioma (o idiomas) empleado, el número total de palabras, la proporción de palabras llenas y vacías, la presencia de la marca y/o producto, la presencia de figuras retóricas, el carácter autónomo del eslogan respecto al logosímbolo, el uso de recursos tipográficos (mayúsculas, cursivas o colores corporativos), la localización en el formato, la orientación del contenido (hacia el producto, el consumidor o la organización) y la presencia de contenidos relativos al ahorro, la economía, el precio o la crisis económica.

\section{Resultados del estudio: evolución de las características del eslogan en la publicidad gráfica española}

Con el análisis de los 400 anuncios encontrados en los 74 números de los 18 soportes seleccionados se ha alcanzado un nivel de exhaustividad suficiente para el logro de los objetivos de la investigación. De hecho, en los últimos números resultaba muy difícil la localización de nuevas unidades a analizar que no hubieran sido ya incorporadas al corpus, alcanzando la saturación que demanda todo análisis de contenido. El número y diversidad de anunciantes representados también parece satisfactorio: 56 del sector de hogar, cosmética y perfumería; 39 de alimentación y bebidas; 38 de moda y complementos; 29 de turismo y viajes; 28 de automoción, 27 de electrodomésticos, muebles y decoración; 22 de joyería y relojería; 19 de seguros y servicios financieros; 17 de medios de comunicación y cultura; 15 de gran distribución y comercio; 11 institucionales, etc.

Los resultados corroboran la tendencia a que los anunciantes empleen cada vez menos el eslogan en el medio prensa. Solo en 242 de los 400 anuncios analizados se ha encontrado algún eslogan, lo que supone un descenso con respecto a resultados anteriores. Si en el año 2000 (v. tabla1) los anuncios con eslogan suponían el 72 por ciento del total y en 2005 el 64,67 por ciento, en 2011 esta cifra desciende al 60,5 por ciento. Esto es especialmente significativo si se considera que el estudio se lleva a cabo en un medio en el que el código escrito sobrevive con más facilidad que en otros en los que la palabra parece haber cedido definitivamente el testigo a la imagen fija o en movimiento. 
Tabla 1. Presencia de eslóganes

Comparativa 2000-2005-2011 (frecuencias y porcentajes)

\begin{tabular}{|l|c|c|c|c|c|c|}
\hline & \multicolumn{2}{|c|}{2000} & \multicolumn{2}{c|}{2005} & \multicolumn{2}{c|}{2011} \\
\hline & Frecuencia & Porcentaje & Frecuencia & Porcentaje & Frecuencia & Porcentaje \\
\hline Anuncios sin eslogan & 86 & 28,00 & 106 & 35,33 & 158 & 39,50 \\
\hline Anuncios con eslogan & 221 & 72,00 & 194 & 64,67 & 242 & 60,50 \\
\hline Totales & 307 & 100,00 & 300 & 100,00 & 400 & 100,00 \\
\hline
\end{tabular}

En suma, 158 de los 400 anuncios analizados carecen de eslogan, frente a los 242 que sí lo incorporan. Si en la investigación de 2005 habían desaparecido aquellos anuncios que portaban dos o más eslóganes, en 2011 se han localizado cinco anuncios con doble eslogan, por lo que el total de eslóganes analizados se eleva a 247, de los cuales, 237 corresponden a anuncios con un único eslogan, y diez a anuncios en los que se han localizado dos eslóganes. Este fenómeno del doble eslogan permite que determinados anunciantes puedan emplear simultáneamente el eslogan de la marca junto con el del producto. Así sucede con el fabricante de relojes TAGHeuer, que emplea el eslogan descriptivo «Swiss Avant-garde since 1860» para la marca genérica y «History begins every morning» para la Serie Carrera. Similar estrategia conduce a la compañía de seguros DKV a simultanear dos esló-

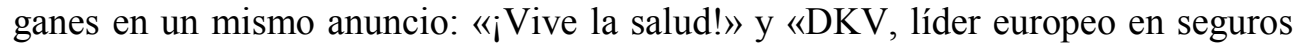
de salud». El primero es propio de la campaña mientras que el segundo, también descriptivo, es permanente y orientado a la organización. Otras veces, simplemente se acumulan dos eslóganes: «El corazón de la dieta mediterránea» $\mathrm{y}$ «Con todo tu amor» (Gobierno de España). En todo caso, debe insistirse en la escasez de uso de esta posibilidad.

\subsection{Economía comunicativa: brevedad}

La brevedad comunicativa es una cualidad de la publicidad actual, que desdeña los largos textos que antaño se prodigaban en la publicidad en prensa. El eslogan, considerado «la quintaesencia» del mensaje publicitario (Bassat, 1994: 124), no es ajeno a esta tendencia, y ha visto decrecer el número de palabras que lo componen. Si en 1988 la publicidad gráfica española presentaba una media de 5,16 palabras en cada eslogan (Díez de Santos y Galán, 1988), en el año 2000 se alcanzaron 4,36 (Garrido, 2000) y solo 3,97 en 2005 (Garrido y Ramos, 2006). Evidentemente, la eficacia de un eslogan no se mide por su extensión, «sino por la calidad con que 
contribuye a los intereses del anunciante» (Curto, 2008: 140), pero no es menos cierto que los anunciantes apuestan por eslóganes muy breves en la publicidad actual.

No es función del eslogan llamar la atención del lector, para ello están los titulares o reclamos. El eslogan goza de gran autonomía, pues su tarea es cerrar el mensaje. Además, acompaña a la marca y ayuda a recordarla (Sabaté, 1997: 65). Esto último estimula su perdurabilidad, y permite que el mismo eslogan sea empleado durante años para los distintos productos o servicios anunciados de un mismo anunciante. En suma, el eslogan actual hereda de la retórica clásica la tendencia a culminar los mensajes con una expresión breve y memorable, la peroratio, que resuma brillantemente lo argumentado en el discurso previo (Spang, 1991). Además, entronca con una larga tradición popular de uso de refranes o sentencias que en muchos casos servían para concluir una argumentación.

A tenor de los resultados de la investigación, los eslóganes empleados en la publicidad gráfica española siguen siendo muy breves, presentan una media de 4,59 palabras. Este dato es ligeramente superior al resultado de 2005 y muy similar al de 2000, lo que parece sugerir una estabilización, incluso un ligero repunte, de la extensión de este recurso en prensa, y es sensiblemente inferior a las 5,16 palabras de media del estudio de Díez de Castro y Galán de 1988.

En el gráfico 1 puede observarse la distribución detallada de los eslóganes según el número de palabras que lo componen, y se comparan dichos resultados con los alcanzados en los estudios de 1988 (Díez de Castro y Galán, 1988), 2000 (Garrido, 2000) y 2005 (Garrido y Ramos, 2005). Los 247 eslóganes analizados en 2011 suman un total de 1.136 palabras, distribuidas principalmente en eslóganes de tres, cuatro y cinco palabras, al igual que sucedía en 2005. Según los resultados correspondientes a 2011, los eslóganes más frecuentes están compuestos por cuatro palabras (20,64 por ciento), seguido de los de tres (18,21 por ciento) y los de cinco (17,41 por ciento). Los tres tipos suponen el 56,26 por ciento del total de eslóganes, por lo que más de la mitad de los eslóganes de la publicidad gráfica española se compone según una de estas tres opciones. Debe destacarse también un crecimiento del número de eslóganes de más de seis palabras, habiéndose encontrado seis eslóganes de once y más palabras. El más largo, con catorce palabras, se encuentra en un anuncio de la aseguradora Verti («La primera compañía de seguros que te garantiza el precio los tres primeros años»), seguido de las trece palabras del eslogan del Club de Vinos del diario El País («La forma más inteligente de disfrutar, aprender y comprar vino desde tu hogar») y las doce del eslogan de la revista Emprendedores («La revista de economía más vendida. La más leída. La número uno»). Curiosamente, en estos tres casos, el componente económico tiene una presencia destacada. Sin embargo, lo normal es que haya eslóganes de tres palabras: «luz.gas.personas» (Endesa), de cuatro: «The best or nothing» (MercedesBenz) y de cinco: «El otro lado de París» (Rochas). También se observa un acusado empleo de eslóganes compuestos por una sola palabra: «Together» (Bacardí), «¿Conectamos?» (The Phone House) y «adelante» (BBVA). 
Gráfico 1. Número de palabras en los eslóganes.

Comparativa 1988-2000-2005-2011 (porcentajes) $\square$

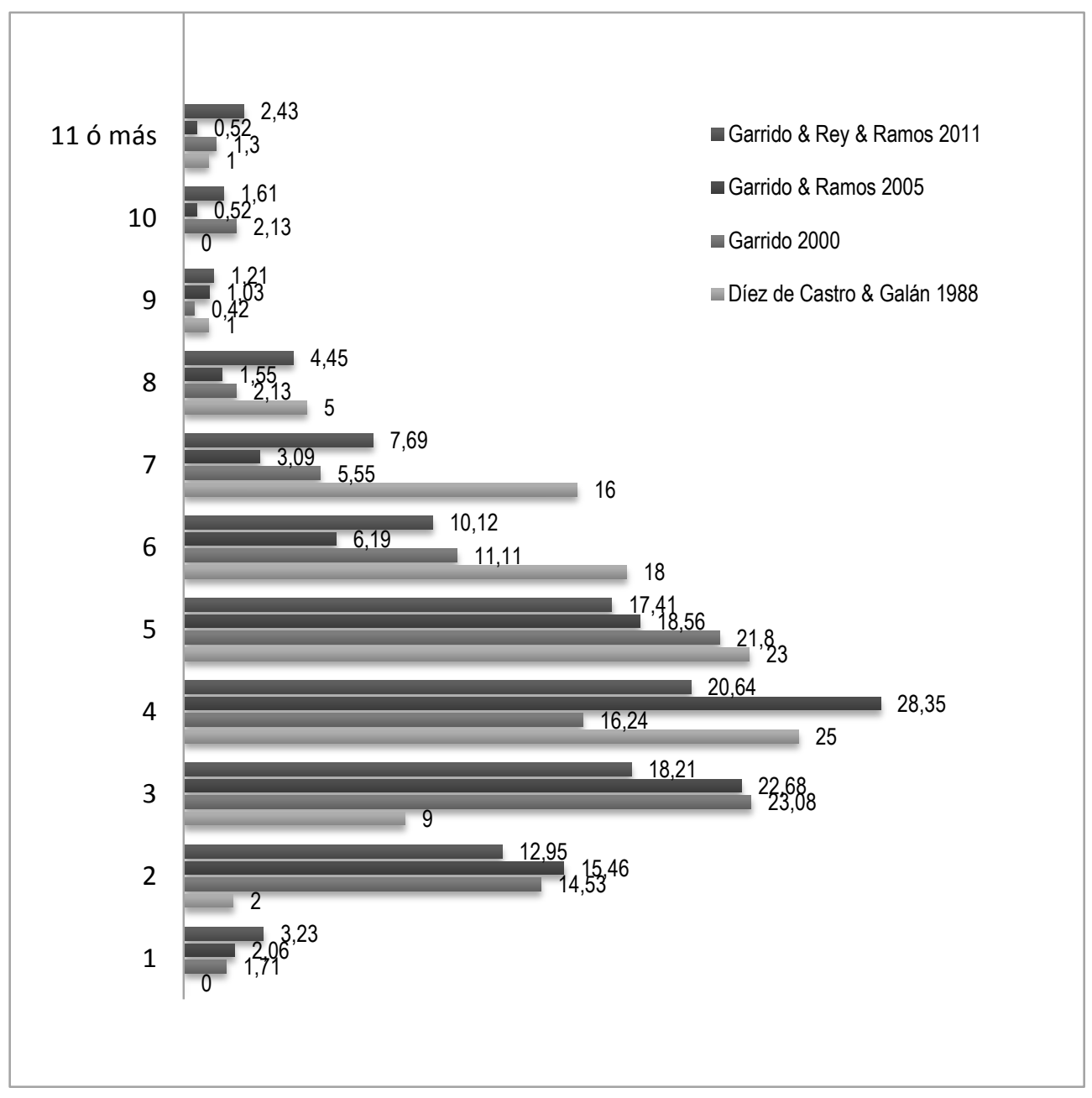

\subsection{Densidad semántica}

La redacción publicitaria elimina todo lo accesorio en beneficio de lo fundamental. Los orígenes de la publicidad en prensa (el anuncio por palabras) explicarían esta tendencia a suprimir los elementos que aportan menos significado (las palabras vacias) y a enfatizar aquellas que más aportan (las plenas). Todo ello en aras de una comunicación más rápida $\mathrm{y}$, en algunos casos, más económica. Esto conlleva que el discurso publicitario se caracterice por la elipsis y la puntuación enfática, generando textos en los que abundan los sustantivos 
porque son las palabras que mayor información proporcionan (principio de economía redaccional). Este abuso da lugar a frases desestructuradas. Y esta desestructuración desemboca en una forma de puntuación muy alejada de las convenciones gráficas al uso» (Curto,2008: 149).

En consecuencia, el eslogan español abusa de las palabras plenas (sustantivos, verbos y adjetivos) en detrimento de las vacías (pronombres, preposiciones, conjunciones, etc.), generando una destacable concentración expresiva en dicha frase.

Tabla 2. Relación entre palabras plenas y vacías

Comparativa 1988-2000-2005 (porcentajes)

\begin{tabular}{|l|c|c|c|c|}
\hline & $\begin{array}{c}\text { Díez de Castro } \\
\text { \& Galán } \\
(1988)\end{array}$ & $\begin{array}{c}\text { Garrido } \\
(2000)\end{array}$ & $\begin{array}{c}\text { Garrido \& Ra- } \\
\text { mos } \\
(2005)\end{array}$ & $\begin{array}{c}\text { Garrido \& Rey } \\
\text { \& Ramos } \\
(2011)\end{array}$ \\
\hline Palabras plenas (\%) & 45,16 & 57,11 & 60,18 & 62,50 \\
\hline Palabras vacías (\%) & 54,84 & 42,89 & 39,82 & 37,50 \\
\hline \multicolumn{1}{|c|}{ Total (\%) } & 100,00 & 100,00 & 100,00 & 100,00 \\
\hline $\begin{array}{l}\text { Media palabras } \\
\text { plenas }\end{array}$ & 2,33 & 2,49 & 2,39 & 2,87 \\
\hline $\begin{array}{l}\text { Media palabras } \\
\text { vacías }\end{array}$ & 2,83 & 1,87 & 1,58 & 1,72 \\
\hline Media palabras total & 5,16 & 4,36 & 3,97 & 4,59 \\
\hline $\begin{array}{l}\text { Relación palabra } \\
\text { plena-palabra vacía }\end{array}$ & 0,82 & 1,33 & 1,51 & 1,67 \\
\hline
\end{tabular}

En nuestra investigación sobre el eslogan en 2011 (v. tabla2), destaca la presencia de palabras plenas, pues suponen el 62,50 por ciento del total, frente a las vacías, que alcanzan solo el 37,50 por ciento. Este dato es mínimamente superior al 60,18 por ciento de palabras plenas de 2005 , al 57,11 de 2000 y, por supuesto, al 45,16 de 1988, y corrobora la tendencia a la concentración semántica que se viene produciendo en el eslogan español durante las dos últimas décadas. Ello es especialmente significativo si se tiene en consideración que en 2011 el número medio de palabras por eslogan se ha incrementado ligeramente. En suma, en los últimos veinte años se ha duplicado la proporción entre palabras plenas y vacías, pasando de 0,82 palabras plenas por cada palabra vacía en 1988 a 1,67 en 2011. Si se acepta que el estilo denso literario se logra con una relación de una palabra plena por cada tres vacías (Haas, 1966: 263), la redacción publicitaria alcanza en el eslogan su mayor densidad. 


\subsection{Creatividad y retórica}

La persuasión es el objetivo último de la comunicación publicitaria. Si la retórica es comúnmente aceptada como el arte de la persuasión, parece lógico que la publicidad recurra habitualmente a los recursos que la retórica ofrece. La configuración completa de un anuncio de gran formato exige el dominio de las técnicas retóricas, si bien no es este el lugar para su exposición. No obstante, en este estudio se focaliza la atención en el empleo de figuras retóricas en los eslóganes, al tratarse del recurso retórico más potente que se aplica sobre una única frase. El punto de partida es doble: por una parte, la definición de figura retórica proporcionada por Spang, quien la entiende como «una modificación consciente del uso normal y corriente de la lengua que lleva a una configuración artísticamente innovadora» (1991: 127); y por otra, el catálogo de figura que este mismo autor recoge en Fundamentos de retórica literaria y publicitaria (1991).

En 110 de los 247 eslóganes analizados se han localizados figuras retóricas, es decir, en el 44,53 por ciento de los mismos. Este dato corrobora la tendencia a emplear cada vez más recursos retóricos en el eslogan, pues supera el 41,74 por ciento del estudio de 2005 y el 26,50 por ciento de 2000. Puede decirse que anunciantes y agencias apuestan cada vez más por dotar de brillantez a los eslóganes empleados en la publicidad gráfica española en prensa.

En la tabla3 se muestran, ordenados alfabéticamente y según la mencionada nomenclatura de Spang (1991), algunos de los recursos encontrados en los eslóganes analizados en esta investigación. Las figuras predominantes son las de repetición (como la anáfora) y, muy especialmente, las de amplificación (antítesis, hipérbole, derivación, etc.), junto a algunos tropos clásicos como la metáfora, la metonimia o la personificación. Como puede observarse, algunos de estos eslóganes podrían clasificarse en varias tipologías, al concentrar en su seno diversos recursos de manera simultánea.

Tabla 3. Figuras retóricas en los eslóganes de la publicidad gráfica española (muestrario)

\begin{tabular}{|c|c|c|}
\hline FIGURA & ANUNCIANTE & ESLOGAN \\
\hline Anáfora & $\begin{array}{l}\text { ORBYT } \\
\text { Natura Bissé } \\
\text { Hyundai } \\
\text { Lancel }\end{array}$ & $\begin{array}{l}\text { En cualquier momento, en cualquier lugar y en } \\
\text { cualquier soporte } \\
\text { My skin. My secret } \\
\text { New thinking. New possibilities } \\
\text { L'art, l'amour, la mode }\end{array}$ \\
\hline Antítesis & $\begin{array}{l}\text { Gran Meliá } \\
\text { Cuervo y Sobrinos } \\
\text { Yves Saint Laurent } \\
\text { Hermés } \\
\text { Confianza Online }\end{array}$ & $\begin{array}{l}\text { Lujo tradicional con estilo vanguardista } \\
\text { El único reloj suizo de alta gama con auténtica } \\
\text { alma latina } \\
\text { La más ardiente de las aguas frescas } \\
\text { Extrait de la terre et du ciel } \\
\text { Nuestro pequeño sello cada día es más grande }\end{array}$ \\
\hline
\end{tabular}


Tabla 3. Figuras retóricas en los eslóganes de la publicidad gráfica española (muestrario)

\begin{tabular}{|c|c|c|}
\hline FIGURA & ANUNCIANTE & ESLOGAN \\
\hline Antonomasia & $\begin{array}{l}\text { Volkswagen } \\
\text { Cadena Ser } \\
\text { Vueling } \\
\text { Scavolini }\end{array}$ & $\begin{array}{l}\text { Das Auto } \\
N^{o} 1 \text { en deporte } \\
\text { Flying hoy means vueling } \\
\text { Scavolini, el número uno italiano en su casa }\end{array}$ \\
\hline Asíndeton & Endesa & Luz. Gas. Personas \\
\hline Asonancia & $\begin{array}{l}\text { Ayuntamiento de Sevi- } \\
\text { lla }\end{array}$ & Sevilla. Se ve \\
\hline Calambur & Vivesoy & $\begin{array}{l}\text { Vivesoy. Lo que vives hoy, lo disfrutarás maña- } \\
\text { na }\end{array}$ \\
\hline Corrección & Pascual & $\begin{array}{l}\text { La calidad de Leche Pascual no tiene secretos. } \\
\text { Tiene razones }\end{array}$ \\
\hline Derivación & $\begin{array}{l}\text { KIA } \\
\text { Pescanova } \\
\text { INGDirect }\end{array}$ & $\begin{array}{l}\text { Un coche extraordinario para gente extraordi- } \\
\text { nariamente normal } \\
\text { Lo bueno sale bien } \\
\text { Un Gran Banco que hace Fresh Banking }\end{array}$ \\
\hline Elipsis & $\begin{array}{l}\text { El Corte Inglés } \\
\text { Volvo } \\
\text { Nespresso }\end{array}$ & $\begin{array}{l}\text { Ven. Elige. Disfruta } \\
\text { Volvo. For life } \\
\text { Café, cuerpo y alma }\end{array}$ \\
\hline Epanadiplosis & $\begin{array}{l}\text { Mapfre } \\
\text { Cadena Ser }\end{array}$ & $\begin{array}{l}\text { Personas que cuidan de personas } \\
\text { Un equipo. Pase lo que pase }\end{array}$ \\
\hline Epífora & The Singular Kitchen & $\begin{array}{l}\text { Cocinas singulares para gente Singular. Are } \\
\text { you Singular? }\end{array}$ \\
\hline Epíteto & Iuvena & Create fresh, new skin \\
\hline Etopeya & $\begin{array}{l}\text { Comunidad Valenciana } \\
\text { IKEA } \\
\text { Magnum } \\
\text { BMW } \\
\text { The Phone House } \\
\text { El Corte Inglés }\end{array}$ & $\begin{array}{l}\text { Te doy todo } \\
\text { ¡Viva la República Independiente de mi Casa! } \\
\text { ¿Buscas placer? } \\
\text { ¿Te gusta conducir? } \\
\text { ¿Conectamos? } \\
\text { ¿Lo tienes? }\end{array}$ \\
\hline Gradación & $\begin{array}{l}\text { FROM } \\
\text { Toyota } \\
\text { Asocama }\end{array}$ & $\begin{array}{l}\text { Por nuestro pescado de hoy y de mañana } \\
\text { Today. Tomorrow. Toyota } \\
\text { Porque durmiendo bien, vivirás mejor }\end{array}$ \\
\hline Hipérbole & $\begin{array}{l}\text { TAGHeuer } \\
\text { Bóboli } \\
\text { Guerlain } \\
\text { Fluchos } \\
\text { Havaianas }\end{array}$ & $\begin{array}{l}\text { History begins every morning } \\
\text { Descubre el mundo con Bóboli } \\
\text { Una fuerza infinita de vida } \\
\text { Comodidad absoluta } \\
\text { Siempre verano }\end{array}$ \\
\hline
\end{tabular}


Tabla 3. Figuras retóricas en los eslóganes de la publicidad gráfica española (muestrario)

\begin{tabular}{|c|c|c|}
\hline FIGURA & ANUNCIANTE & ESLOGAN \\
\hline Metáfora & $\begin{array}{l}\text { Gobierno de España- } \\
\text { Aceite de Oliva } \\
\text { Ariete } \\
\text { Royal Caribbean Cru- } \\
\text { ceros } \\
\text { Mar de Frades } \\
\text { Meliá Hoteles } \\
\text { Zespri }\end{array}$ & $\begin{array}{l}\text { El corazón de la dieta mediterránea } \\
\text { Il genio della casa } \\
\text { País del por qué no } \\
\text { Un mar que es un vino } \\
\text { El viaje eres tú } \\
\text { El rey de las vitaminas }\end{array}$ \\
\hline Metonimia & $\begin{array}{l}\mathrm{H} \& \mathrm{~S} \\
\text { QUO }\end{array}$ & $\begin{array}{l}\text { Por una cabeza más feliz } \\
\text { La revista para mentes inquietas }\end{array}$ \\
\hline Paralelismo & $\begin{array}{l}\text { Prisa } \\
\text { Nestlé }\end{array}$ & $\begin{array}{l}\text { Conecta tu marca. Amplifica tu mensaje } \\
\text { Empieza bien. Crece sano }\end{array}$ \\
\hline Personificación & $\begin{array}{l}\text { Adolfo Domínguez } \\
\text { Abripool } \\
\text { Mayoral } \\
\text { Rexona } \\
\text { Roca } \\
\text { TRESemmé } \\
\text { Prima } \\
\text { ENEL }\end{array}$ & $\begin{array}{l}\text { La música que te viste } \\
\text { La cubierta amiga } \\
\text { Mayoral hace amigos } \\
\text { Rexona. No te abandona } \\
\text { Roca loves the planet } \\
\text { Nacido en peluquerías internacionales } \\
\text { El sabor siempre joven } \\
\text { La energía que te escucha }\end{array}$ \\
\hline Rima & $\begin{array}{l}\text { Havana Club } \\
\text { Olay }\end{array}$ & $\begin{array}{l}\text { No hay nada como Havana } \\
\text { Probado. Potente. Olay Profesional }\end{array}$ \\
\hline
\end{tabular}

La expresividad de un eslogan no solo se refuerza mediante el uso de figuras retóricas, también se recurre a diversos recursos tipográficos que añaden significado extra al contenido de la frase o, simplemente, lo destacan visualmente. Con esta intención, es habitual encontrar eslóganes compuestos con letras mayúsculas, tal y como sucede con titulares o reclamos publicitarios. En el presente estudio, el 30,77 por ciento de los eslóganes emplea este recurso, porcentaje inferior al 34,02 por ciento de 2005 y al 35,04 por ciento de 2000. También ha descendido, aunque ligeramente, el porcentaje de eslóganes que emplea las mayúsculas en las letras iniciales de las palabras plenas, pasando del 10,82 por ciento de 2005 al 9,72 de 2011, y ello a pesar del crecimiento de los eslóganes en inglés, pues es bien conocida la tradición anglosajona de empleo de este recurso. He aquí algunos: «La Publicidad Inteligente» (Comfersa), «Carrefour en Positivo» (Carrefour), «El Festival de los Momentos Mágicos» (Disneyland París), «Made with Love» (Wonders) o «The Power of Dreams» (Honda).

En general, el empleo de las minúsculas se viene imponiendo paulatinamente en el discurso publicitario, por lo que resulta lógico que también los eslóganes, al igual que los nombres de marca, se vayan desprendiendo de la magnificencia de las mayúsculas y apuesten por un estilo comunicativo más sencillo y más próximo a sus públicos. De este modo, el 21,45 por ciento de los eslóganes analizados en 
2011 se inicia con minúsculas, dato muy superior al 13,20 por ciento de 2005 . Este mecanismo, que transmite una imagen cercana del anunciante, puede apreciarse en los siguientes eslóganes: «adelante» (BBVA), «flying hoy means vueling» (Vueling), «nos comprometemos» (Darty), «precio hipermejor» (Hipercor) o «time to come» (Marea). Tan frecuente es su empleo que los usos expresivos de mayúsculas y minúsculas en el discurso publicitario han sido recogidos en la Ortografia de la Lengua Española (1999: 39) de la Real Academia Española.

Otro recurso tipográfico que habitualmente se encuentra en los eslóganes es la cursiva. En concreto, el 8,50 por ciento de los eslóganes analizados en 2011 lo emplea, cifra muy inferior al 13,92 por ciento de 2005 o al 15,81 de 2000. A pesar de dicho descenso, se sigue empleando para enfatizar la idea: «iVive la salud!» (DKV), otorgar tradición: «Forever Fashionable since 1820» (Beefeater) y, sobre todo, para transmitir emociones: «El viaje eres tú» (Meliá), «Empieza bien. Crece sano» (Nestlé Crecimiento), «Nos importas tú» (Confortel) o «¿Buscas placer?» (Magnum). La proximidad (visual y conceptual) entre el logosímbolo y el eslogan conlleva también que en numerosas ocasiones los eslóganes incorporen total o parcialmente los colores corporativos de la marca en su tipografía, lo que sucede en el 34,01 por ciento de los eslóganes, porcentaje idéntico al de 2005 (34,02 por ciento), siendo indicativo de la estabilidad de su uso en uno de cada tres anuncios con eslogan.

Un aspecto interesante del estudio es la presencia de lenguas distintas al español en los eslóganes de la publicidad gráfica española. Llama la atención, tanto en el actual estudio de 2011 como en los anteriores, la ausencia de eslóganes que en catalán, gallego o vasco. Sin embargo, la presencia de eslóganes en idiomas extranjeros se ha multiplicado por dos en algo más de una década, alcanzando el 30,36 por ciento del total en 2011. El inglés es, sin duda, el que más se emplea, pues se ha convertido en la lengua de la sociedad global, especialmente en el ámbito comercial. En la actualidad, uno de cada cuatro eslóganes de la publicidad gráfica española (el 25,91 por ciento) se publica en inglés, superando los datos de 2005 ( 24,75 por ciento) y 2000 ( 14,53 por ciento). En algunos casos, se trata de multinacionales que, sin más, incorporan su eslogan tal y como lo emplean en todo el mundo: «For successful living》 (Diesel) o «The best or nothing» (Mercedes-Benz). Sin embargo otras veces se trata de empresas españolas que adoptan este idioma para su comunicación publicitaria: «The original» (Silestone) o «Roca loves the planet» (Roca). También se han encontrado hasta cinco eslóganes en los que se simultanea el uso del inglés y el castellano en la misma frase, así ocurre con: «flying hoy means vueling» (Vueling), «El mundo con tarifas económicas by AirFrance» (AirFrance) o «Cocinas Singulares para gente Singular. Are you singular?» (The Singular Kitchen). Sin duda, la compañía aérea de bajo coste Vueling es la que ha popularizado el spanglish en la publicidad española. También se han localizado cinco eslóganes en francés: «Créative Technologie» (Citroën) o «Extrait de la terre et du ciel» (Hermés); tres en italiano: «Sportivo» (Armani) o «Benvenuti a casa» (Natuzzi); y dos en alemán: «Das Auto» (Volkswagen) o «Wir 
leven Autos» (Opel). Como puede observarse, el uso de idiomas distintos al castellano o el inglés sigue siendo muy minoritario, y restringido a anunciantes cuya nacionalidad justifica dicho empleo.

\subsection{El valor de la exclusividad}

El eslogan nace para perdurar, como sucede con el popular «Porque yo lo valgo», de L'Oréal, o el conocido «¿Te gusta conducir?» de BMW. Y es precisamente el uso continuado del mismo eslogan el que permite la asociación de la marca con los valores que transmite y la exclusividad de su empleo. Otro factor que otorga exclusividad al eslogan, es, lógicamente, la inclusión del propio nombre de marca en la frase, con lo que se evita «que otro competidor pueda en la práctica hacer uso del mismo» (Ortega, 1997: 254). Esta posibilidad, habitual en la publicidad de hace varias décadas, apenas se encuentra en el diez por ciento de los eslóganes actuales, exactamente en el 8,91 por ciento de los eslóganes analizados (v. tabla4). Ejemplos de ello son «Carrefour en Positivo», «Mayoral hace amigos» o «Today. Tomorrow. Toyota». Algo más común resulta el empleo del producto o servicio anunciado en el eslogan (16,19 por ciento), como sucede con «Seguros para la vida real» (Reale) o «El único reloj suizo de alta gama con auténtica alma latina» (Cuervo y Sobrinos). Y lo más raro es encontrar simultáneamente el nombre de marca junto con el producto genérico anunciado, pues este recurso solo aparece en el 1,62 por ciento del total de eslóganes: por ejemplo, en «DKV, líder europeo en seguros de salud» $\mathrm{y}$ en «BIO, el canal de las celebrities».

Tabla 4. Presencia de nombre de marca y/o producto en el eslogan

Comparativa 2000-2005-2011

\begin{tabular}{|l|c|c|c|c|c|c|}
\hline & $\begin{array}{c}\text { Frecuencia } \\
\mathbf{2 0 0 0}\end{array}$ & $\begin{array}{c}\text { Porcentajes } \\
\mathbf{2 0 0 0}\end{array}$ & $\begin{array}{c}\text { Frecuencia } \\
\mathbf{2 0 0 5}\end{array}$ & $\begin{array}{c}\text { Porcentajes } \\
\mathbf{2 0 0 5}\end{array}$ & $\begin{array}{c}\text { Frecuencia } \\
\mathbf{2 0 1 1}\end{array}$ & $\begin{array}{c}\text { Porcentajes } \\
\mathbf{2 0 1 1}\end{array}$ \\
\hline $\begin{array}{l}\text { Presencia de } \\
\text { producto gené- } \\
\text { rico }\end{array}$ & 55 & 23,50 & 26 & 13,40 & 40 & 16,19 \\
\hline $\begin{array}{l}\text { Presencia de } \\
\text { marca y/o mode- } \\
\text { lo }\end{array}$ & 22 & 9,40 & 11 & 5,67 & 22 & 8,91 \\
\hline $\begin{array}{l}\text { Presencia de } \\
\text { producto genéri- } \\
\begin{array}{l}\text { co y marca y/o } \\
\text { modelo }\end{array}\end{array}$ & 4 & 1,71 & 0 & 0,00 & 4 & 1,62 \\
\hline $\begin{array}{l}\text { Ninguno de los } \\
\text { anteriores }\end{array}$ & 153 & 65,39 & 157 & 80,93 & 181 & 73,27 \\
\hline Totales & 234 & 100,00 & 194 & 100,00 & 247 & 100,00 \\
\hline
\end{tabular}




\subsection{El posicionamiento seleccionado}

Al concebir un eslogan para un anunciante, la primera decisión que debe adoptarse desde el punto de vista estratégico es el posicionamiento del mismo. En general, tres son las grandes orientaciones que puede tener un eslogan: hacia el producto o servicio anunciado, hacia el consumidor y su universo, y, finalmente, hacia la propia organización. Si hace unas décadas era normal que la mayoría de eslóganes se centraran en los productos o servicios anunciados, los estudios de las necesidades de los consumidores así como la preponderancia de las estrategias de brand personality han conducido a que muchos eslóganes se centren ahora en el consumidor o en la marca. Como puede observarse en el gráfico 2, aunque de forma moderada, son ya más los eslóganes que focalizan su interés en el consumidor (el 38,87 por ciento) que aquellos que versan sobre el producto o servicio anunciado (el 38,05 por ciento). Esta mínima diferencia difiere de los resultados alcanzados en 2000, cuando los eslóganes centrados en el producto o servicio superaban en diez puntos porcentuales a aquellos cuyo contenido se dedicaba a los consumidores o usuarios. Como se observa, esta diferencia no existe hoy día, y el consumidor ha ganado un gran protagonismo, no solo en los eslóganes, también en el mensaje publicitario en su totalidad. Por su parte, los eslóganes corporativos, es decir, aquellos cuyo posicionamiento tiene que ver con la propia organización anunciante, mantienen un porcentaje similar al del estudio de 2005, exactamente, el 31,08 por ciento del total.

Gráfico 2. Orientación del contenido del eslogan.

Comparativa 2000-2005-2011 (en porcentajes)

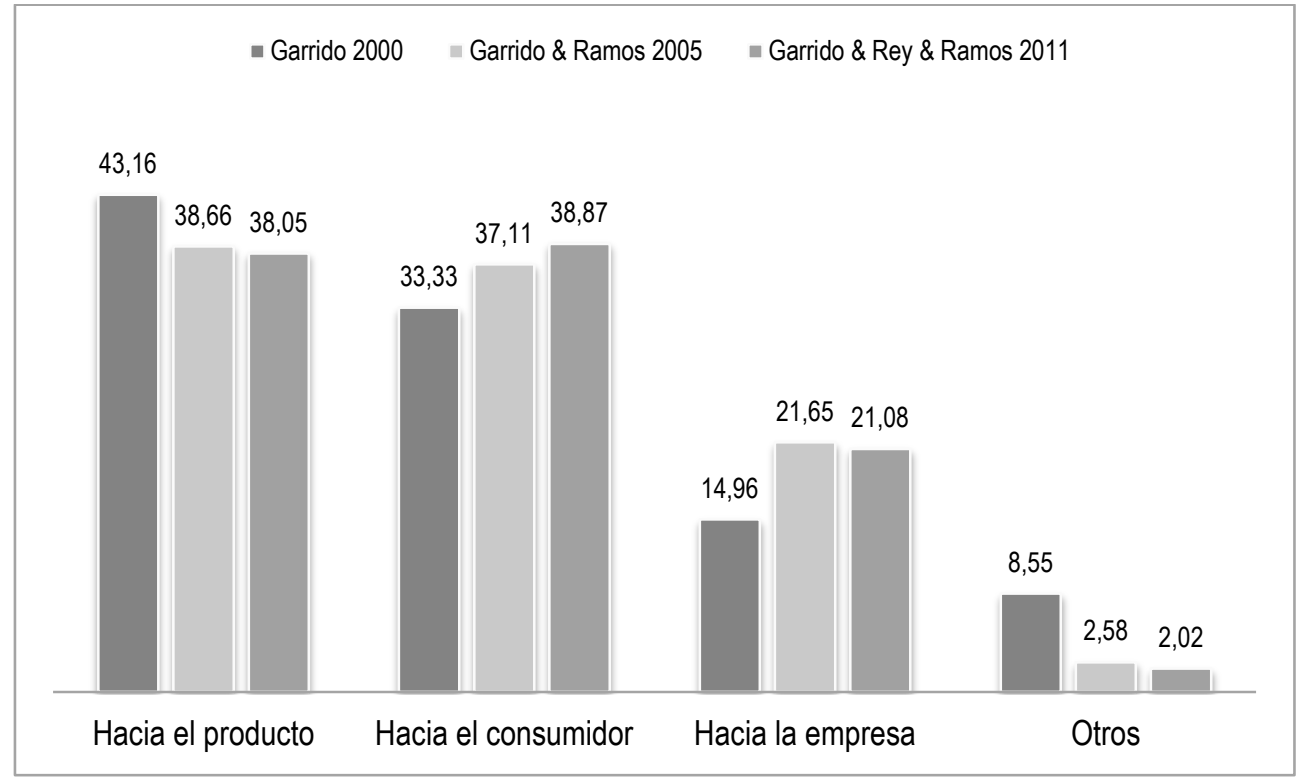




\subsection{La localización en el formato}

En líneas generales, la redacción publicitaria sigue siendo bastante respetuosa con la superestructura clásica de un anuncio de gran formato para el medio prensa (Rey, 1996). Según estas pautas, el eslogan cierra el mensaje (junto con el logosímbolo del anunciante) conceptual y visualmente. En teoría, estos dos elementos deben ser los últimos leídos por quien haya procedido a la lectura completa del anuncio, lo cual sucede cada vez en menos ocasiones de las deseadas por los creativos. En consecuencia, si se tiene en consideración la curva de lectura natural de todo anuncio, el eslogan, al igual que el logotipo, debe situarse en la parte inferior derecha del anuncio. Esto garantiza una correcta atribución de la función de dicha unidad redaccional por el lector, acostumbrado a encontrarlo en dicha posición. Según los datos recogidos en la tabla5, dos de cada cuatro eslóganes se encuentran en la parte inferior derecha del anuncio (exactamente, el 54,6 por ciento en el estudio de 2011), proporción que se eleva a cuatro de cada cinco si tiene en cuenta toda la franja inferior del anuncio (el 81,4 por ciento). El análisis comparativo de los resultados que sobre esta cuestión se han alcanzado en los estudios de 2000, 2005 y 2011 no detecta grandes diferencias entre ellos. Por otra parte, el eslogan mantiene cierta independencia con respecto al logosímbolo en dos de cada tres anuncios, pues el 63,56 por ciento de estas frases funcionan al margen de la marca. Solo noventa eslóganes se integran visualmente con el logosímbolo conformando una unidad indisoluble.

Tabla 5. Distribución física del eslogan

Comparativa 2000-2005-2011 (porcentajes)

\begin{tabular}{|c|c|c|c|c|c|c|c|}
\hline $\begin{array}{c}\text { Porcentaje } \\
2000\end{array}$ & $\begin{array}{c}\text { Porcentaje } \\
2005\end{array}$ & $\begin{array}{c}\text { Porcentaje } \\
2011\end{array}$ & \multicolumn{2}{|c|}{ Localización en el anuncio } & $\begin{array}{c}\text { Porcentaje } \\
2000\end{array}$ & $\begin{array}{c}\text { Porcentaje } \\
2005\end{array}$ & $\begin{array}{c}\text { Porcentaje } \\
2011\end{array}$ \\
\hline \multirow{3}{*}{14,10} & \multirow{3}{*}{17,00} & \multirow{3}{*}{17,80} & \multirow{3}{*}{$\begin{array}{c}\text { Tercio } \\
\text { superior }\end{array}$} & $\begin{array}{l}\text { Tercio iz- } \\
\text { quierdo }\end{array}$ & 3,40 & 4,10 & 5,30 \\
\hline & & & & $\begin{array}{l}\text { Tercio cen- } \\
\text { tral }\end{array}$ & 3,80 & 1,00 & 5,30 \\
\hline & & & & $\begin{array}{l}\text { Tercio dere- } \\
\text { cho }\end{array}$ & 6,90 & 11,90 & 7,20 \\
\hline \multirow{3}{*}{4,90} & \multirow{3}{*}{4,10} & \multirow{3}{*}{0,80} & \multirow{3}{*}{$\begin{array}{l}\text { Tercio } \\
\text { central }\end{array}$} & $\begin{array}{c}\text { Tercio iz- } \\
\text { quierdo }\end{array}$ & 0,10 & 1,60 & 0,00 \\
\hline & & & & $\begin{array}{l}\text { Tercio cen- } \\
\text { tral }\end{array}$ & 1,70 & 1,60 & 0,40 \\
\hline & & & & $\begin{array}{l}\text { Tercio dere- } \\
\text { cho }\end{array}$ & 3,10 & 0,90 & 0,40 \\
\hline \multirow{3}{*}{81,00} & \multirow{3}{*}{78,90} & \multirow{3}{*}{81,40} & \multirow{3}{*}{$\begin{array}{l}\text { Tercio } \\
\text { inferior }\end{array}$} & $\begin{array}{c}\text { Tercio iz- } \\
\text { quierdo }\end{array}$ & 10,30 & 11,90 & 14,20 \\
\hline & & & & $\begin{array}{l}\text { Tercio cen- } \\
\text { tral }\end{array}$ & 14,50 & 11,30 & 12,60 \\
\hline & & & & $\begin{array}{l}\text { Tercio dere- } \\
\text { cho }\end{array}$ & 56,20 & 55,70 & 54,60 \\
\hline 100,00 & 100,00 & 100,00 & \multicolumn{2}{|c|}{ Totales } & 100,00 & 100,00 & 100,00 \\
\hline
\end{tabular}




\subsection{El componente económico en los eslóganes}

La crisis económica ha incidido en la forma en la que la mayoría de anunciantes se acerca a sus públicos. Muchos consumidores han visto mermados sus ingresos y lógicamente reducen el consumo a la par que redistribuyen de forma óptima el dinero disponible. Es más, aquellos cuyos ingresos no solo no se han reducido sino que pueden haberse incrementado, se muestran dubitativos a la hora de gastar dinero ante las incertidumbres que depara el futuro. Teniendo en consideración este contexto, en este estudio se ha querido conocer de manera secundaria con respecto a su objetivo principal, por un lado, qué proporción de anuncios con eslogan tienen como objetivo principal de comunicación algún aspecto económico, ya sea en forma de promoción de ventas, referencias a la crisis, ofertas y descuentos, etc.; y, por otro, la proporción de eslóganes centrados en este factor económico y la manera en que lo hacen.

En total se han localizado 23 eslóganes en los que la variable económica está presente, lo que supone el 9,31 por ciento del total. Como el eslogan es un elemento que, en principio, suele concebirse a largo plazo dentro de una estrategia de brand personality, el resultado es moderado. Evidentemente, hay eslóganes clásicos en los que esta presencia ya era destacada, como el mencionado «Porque yo lo valgo», de L'Oréal, con el que la marca de cosmética francesa siempre ha intentado derribar el freno que para muchos consumidores supone el elevado precio de sus productos. También parece lógico que determinadas compañías que practican el descuento como filosofía empresarial trasladen esto a sus eslóganes, como sucede con «Los mejores descuentos cerca de ti» (Planeo) o «Si estás buscando un seminuevo, utiliza tus euros con cabeza» (Renault Ocasión).

A pesar de que el resultado es poco representativo desde el punto de vista cuantitativo, sí es interesante descubrir que anunciantes tradicionalmente alejados de estrategias de precios y centrados en valores de marca como la calidad o la exclusividad hayan girado ciento ochenta grados en el contenido de sus eslóganes a favor del ahoro y otras consideraciones de tipo económico. Un ejemplo significativo es el del Grupo El Corte Inglés, que para sus tiendas de electrónica e informática utiliza el eslogan «Atención especializada, 2 años de garantía y siempre con buenos precios», y para Hipercor, además de jugar en la publicidad con la combinatoria de letras entre las palabras Hipercory precio, utiliza el eslogan «Precio hipermejor». Lejos queda ya el eslogan «Hipercor es calidad», utilizado durante décadas. Hay otros ejemplos: «El mundo con tarifas económicas by AirFrance», «La decoración más exclusiva al alcance de todos» $(\mathrm{N} \& \mathrm{~V})$, «Aquí tu dinero vale más» (Worten), «Tú propones el precio» (la Caixa), «Es tu dinero y tú decides» (Banca Cívica), etc.

A veces, el componente económico no está presente en el eslogan pero sí predomina en el resto del anuncio, lo que sucede en el 21,07 por ciento del total de anuncios. Es decir, uno de cada cinco anuncios con eslogan apuesta por una creatividad en la que el ahorro, el precio o la misma crisis se convierten en eje de la 
campaña. Evidentemente, estos resultados, de carácter exploratorio, requieren de contraste en un contexto de crecimiento económico, observando en qué medida estas distintas circunstancias económicas inciden en la mayor o menor presencia de este tipo de contenido en los eslóganes.

\section{Conclusiones}

El presente estudio confirma la desafección creciente de los anunciantes con el eslogan, pues cada vez son más los anuncios de la publicidad española en prensa en los que se renuncia a la incorporación de esta frase. El contexto actual no ha modificado esta tendencia, antes bien parece haberla incrementado, pues en apenas diez años se han perdido casi doce puntos porcentuales de presencia de eslóganes hasta alcanzar el 60,50 por ciento actual. Y ello es especialmente significativo en un medio en el que, a priori, el eslogan tiene más probabilidades de supervivencia por su larga tradición en el empleo del código escrito.

La brevedad sigue siendo la cualidad principal de los eslóganes, pues se mantiene en una media de cuatro palabras. Con una media de palabras tan nimia, la densidad semántica sigue siendo muy elevada, incluso superior a la encontrada en estudios previos. Casi dos de cada tres palabras son plenas, lo que da una idea de este nivel de concentración. En general, también se ha incrementado el empleo de recursos retóricos que persiguen la brillantez de la frase, en detrimento del uso de ciertos artificios tipográficos como mayúsculas o cursivas. El anunciante actual prefiere eslóganes con letra minúscula y con tipografía fácilmente legible, en consonancia con las estrategias de proximidad y cercanía a los consumidores y usuarios. En definitiva, como testimonio de la que publicidad ya solo puede ser bidireccional y dialógica.

La globalización de la comunicación publicitaria ha impulsado un profuso empleo de eslóganes en lengua inglesa en la publicidad española, lo que sucede en uno de cada cuatro casos. De este modo, las marcas se internacionalizan al tiempo que reducen los costes de producción y adaptación consustanciales a la publicidad tradicional, que adapta los mensajes a cada mercado y, consecuentemente, a la lengua dominante en el mismo. Otros dos factores se han incrementado. Por un lado, la inclusión del nombre de marca y/o producto genérico en el contenido del eslogan, propiciando la exclusividad de su uso; y, por otro, la orientación hacia el consumidor, con un leve descenso de los eslóganes centrados en el producto o en la organización. En líneas generales, se mantiene, al igual que en los estudios precedentes, el respeto a la superestructura clásica y distribución de elementos en el anuncio, por lo que el eslogan sigue ocupando la posición inferior (preferentemente, la derecha) en la mayoría de anuncios, confirmando su función de cierre.

Finalmente, un porcentaje pequeño de eslóganes (en torno al diez por ciento) desarrolla contenidos de tipo económico (precio, ahorro, descuento, crisis, etc.). 
Este porcentaje es moderadamente significativo y confirma que el eslogan es una pieza redaccional destinada a perdurar en el tiempo y a conformar la brand personality a largo plazo, y no sujeta a los vaivenes coyunturales. Aunque en muchos casos, la actividad económica del anunciante parece justificar la inclusión de este aspecto en el eslogan, hay otros anunciantes que lo adoptan en este momento. De este modo, algunos anunciantes que antes se posicionaban en la calidad y la exclusividad (el Grupo El Corte Inglés, por ejemplo) ahora lo hacen en el precio y el ahorro.

En suma, este análisis viene a demostrar que se han estabilizado las tendencias observadas en estudios anteriores. Y los cambios que se han detectado, de momento, no resultan estadísticamente significativos. En cualquier caso, sería conveniente proseguir con esta serie de estudios periódicos con el objeto de observar la evolución y desarrollo del eslogan en la publicidad gráfica española.

\section{Referencias bibliográficas}

ADAM, J.M., y BONHOME, M. (2000): La argumentación publicitaria, Madrid, Cátedra.

ALASTAIR, C. (1997): The craft of copywriting, London, Century Business.

ARENS, W.F. (1996): Contemporary advertising, Chicago, Irwin.

BASSAT, L. (1994): El libro rojo de la publicidad, Barcelona, Folio.

BORSTEN, E. (1999): «Jergario», en Moliné, M. (ed.), La fuerza de la comunicación publicitaria, Madrid, Cuadernos Cinco Días, 16-23.

BURTON, P. W. (1990): Advertising Copywriting, Lincolnwood (Illinois), NTC Business Books.

CHAN, R. (2000): «The effectiveness of environmental advertising: the role of claim type and the source country green image», International Journal of Advertising, 19 (3), 349375.

CURTO, V., Rey, J., y SABATÉ, J. (2008): Redacción publicitaria, Barcelona, Editorial UOC.

DíEZ DE CASTRO, E.C., y GALÁN, J.L. (1988): «Análisis del slogan publicitario español», Revista de Economía y Empresa, 8 (22), 99-119.

EguiZÁBAL, R. (2007): Teoría de la publicidad, Madrid, Cátedra.

FAY, M. (1999): «Advertisements as cyclical fashion goods? An analysis of variation in the frequency of usage of values, claims \& styles in magazine advertisements», International Journal of Advertising, 18 (3), 377-404.

FERNÁNDEZ GÓMEZ, J. D. (2005): «Eslóganes, jingles y otras frases felices», en Romero, M.V. (coord.), Lenguaje publicitario. La seducción permanente, Barcelona, Ariel, 89112.

GARRIDO, M. (2000): «El eslogan del año 2000», Questiones Publicitarias, 8, 68-87.

- Y RAMOS, M. (2006): «La evolución del eslogan en la publicidad gráfica española», Trípodos, extra, 183-193.

HAAS, C. R. (1966): Teoría, técnica y práctica de la publicidad, Madrid, Rialp.

HERNÁNDEZ, R. (2007): «Claims: entre la inspiración y el método», Anuncios, 1201, 33.

Hollander, N. (2007): «Eslogan. Claim. Concepto», Anuncios, 1201, 34. 
KEMP, E., BUI, M., y CHAPA, C. (2012): «The role of advertising in consumer emotion management», International Journal of Advertising, 31 (2), 339-353.

MUÑIZ, J.A. (2005): «El papel del eslogan en la actitud hacia la marca. Una tentativa de estudio experimental», Questiones Publicitarias, 10, 119-142.

ORTEGA, E. (1992): La publicidad en televisión. Estilos, slogans, promociones, inversiones, Madrid, Mundi-Prensa.

- et al. (2006): «El eslogan en el sector turístico español», Cuadernos de Turismo, 17, 127-146.

PEÑA, G. (2001): «El valor persuasivo del eslogan publicitario», Círculo de Lingüistica Aplicada a la Comunicación, 6, 85-95.

PRAT GaBAllí, P. (1998): 505 verdades publicitarias, Barcelona, Oikos-Tau.

REAL ACADEMIA ESPAÑOla (1999): Ortografía de la Lengua Española, Madrid, Espasa.

- (2001): Diccionario de la Lengua Española, Madrid, Espasa.

ReBoul, O. (1978): El poder del slogan, Valencia, Fernando Torres Editor.

REY, J. (1996): Palabras para vender, palabras para soñar. Introducción a la redacción publicitaria, Barcelona, Paidós.

SABATÉ, J. (1997): La publicitat, Barcelona, Pòrtic.

SAMUELSEN, B.M.,y OLSEN, L.E. (2010): «Promising attributes and experiences», Journal of Advertising, 39 (2), 65-77.

SPANG, K. (1991): Fundamentos de retórica literaria y publicitaria, Pamplona, EUNSA. 